227. Sevilla : Junta de Andalucía.

CABEZUDO, B. y A. E. SALVO -1987- Psilotum nudum (L.) Beauv. In Valdés, B., Talavera, S., \& Fernández-Galiano, E. (Eds.), Flora Vascular de Andalucía Occidental, Vol. I: 43. Barcelona: Ketres Editora.

GALÁN DE MERA, A., J. A. VICENTE ORELLANA, J. L. GONZÁLEZ y J. C. FERNÁNDEZ LUNA 1996- New Population of Psilotum nudum in SW Europe. Fern Gaz. 15 (3): 109-112.

PÉREZ LATORRE, A. V., A. GALÁN DE MERA, P. NAVAS, D. NAVAS, Y. GIL y B. CABEZUDO
-1999- Datos sobre la flora y vegetación del Parque Natural de los Alcornocales. Acta Bot. Malacitana 24: 133-184. Málaga.

SALVO, E. -1990- Guía de helechos de la península Ibérica y Baleares. Madrid. Pirámide.

Aceptado para su publicación en febrero de 2003

Dirección de los autores A. J. Delgado Vázquez: C/ Sol 43, San Pablo de Buceite, Cádiz.

\title{
93. DOS TAXONES NATURALIZADOS EN LA PENÍNSULA IBÉRICA PRESENTES EN ANDALUCÍA OCCIDENTAL
}

Abelardo APARICIO

Two naturalised taxa in the Iberian Peninsula present in west Andalusia.

Plabras clave. Hibiscus, Solanum, Andalucía.

Key words. Hibiscus, Solanum, Andalusia.

Se citan a continuación dos taxones naturalizados en la flora de la Península Ibérica que se han encontrado en la provincia de Sevilla, donde, según los datos disponibles, no habían sido citados. Los pliegos testigo se encuentran depositados en el herbario de la Universidad de Sevilla (SEV).

\section{Hibiscus trionum L.}

Originaria de América se encuentra actualmente diseminada por el sur de Europa, África, Asia y Australia. En España se encuentra esparcida por algunas provincias del este asociada a lugares húmedos en arrozales y otros regadíos. La hemos localizado en la provincia de Sevilla creciendo abundantemente en lugares húmedos cerca de acequias entre cultivos de algodón.

SEVILLA: Dos Hermanas, proximidades del río Guadaira. Cultivos de algodón y maíz.
UTM 30S 234068-4132393. 1.09.2003, A. Aparicio, F. García Martín \& A. Sousa.

\section{Solanum elaeagnifolium Cav.}

Planta americana, actualmente distribuida por gran parte del mundo, que en la Península Ibérica se localiza por el este español. La hemos encontrado como especie viaria en dos localidades en la provincia de Sevilla.

SEVILLA: Dos Hermanas, proximidades del río Guadaira. UTM 234282-4132388. 1.09.2003; Bormujos, UTM 29S 757234 4138682, 15.11.2003, J. Aparicio \& A. Aparicio.

Aceptado para su publicación en octubre de 2003

Dirección del autor. Departamento de Biología Vegetal y Ecología. Facultad de Farmacia. Universidad de Sevilla. 